\title{
Bridging the Gap Between Industry and Academia in Pharmaceutical Education
}

\author{
Athira Balakrishnan, Girish Thunga*, Sreedharan Nair, Vijayanarayana Kunhikatta, Kanav Khera \\ Department of Pharmacy Practice, Manipal College of Pharmaceutical Sciences, Manipal Academy of Higher Education, Manipal, \\ Karnataka,INDIA.
}

\begin{abstract}
Though Pharmaceutical industries are growing at a rapid rate, Pharmacy curriculum is not taken pharmaceutical industry into consideration. Both industry and academia have different mindsets and goals. Pharma curriculum is mainly oriented towards the conventional needs of an industry which inturn creates a gap between industry and academia. Pharma graduates do not possess adequate skills to meet all industrial requirements. Students should expose more practical experience apart from the theoretical knowledge. As the world is becoming more and more professionally competent, it is paramount to enhance professional standards of graduates to keep their wheel moving. This is possible through industry academia collaboration. Curriculam should be fostered with inclusion of case studies, training programmes, course works, and summer internships programmes. Simulation lab can also be introduced as it is provided realistic training and skills. Academia-industry interaction should consider as part of the education and industries should come forward and align the course contents with their needs. Academia also should bring changes in the educational system to ensure that industry expectation is met without compromising academic goals. This article emphasizes on gap between industry and academy, major flaws of pharma curriculum with respect to pharma industry, and strategies to improve the situation by laying special emphasis on inclusion of training programme.
\end{abstract}

Key words: Pharmaceutical education, Industry, Academia, Training.

Indian pharmaceutical industry is one of the fastest-growing and most lucrative industries in India, with a compounded annual growth rate (CAGR) of $17.46 \%$ during 2005-2016. It is expected to grow at a compounded annual growth rate of $15.92 \%$ to US $\$ 55$ billion by 2020 . At the same time, India is becoming a favorite destination for multinational pharmaceutical companies owing to its low manpower cost, highly qualified graduates and increased infectious disease. By 2020, India is expected to be among the top three pharmaceutical markets by its progressive growth. ${ }^{1}$ This will reflect pharmaceutical job market and pharmaceutical employment will be expanding at a higher rate than the previous years. The pharmaceutical sector will witness a surge in hiring across position and recruitment numbers are poised to continue rising in double digits in the next year. ${ }^{2,3}$ Accepting the fact Indian pharmaceutical industries are growing at rapid rate, it is noticeable that the fresh pharma graduates do not possess adequate professional skills to meet the industrial needs. The reason behind this may be an enormous gap between academia and industries. In India pharmaceutical education is away from the reality. Though industries are the ultimate employer, pharmacy curriculum is not much focused on industry relevant topics. Pharmacy education will not be completed without taking pharma industries into consideration. ${ }^{4}$ Pharmacy courses are mostly intended towards the conventional needs of industry; regulatory requirements of pharmaceutical industry are dynamic, which is not restructured in the curriculum. Cur-
Submission Date: 14-11-17; Revision Date: 13-04-18; Accepted Date: $22-5-18$

DOI: $10.5530 /$ ijper.52.4s.69 Correspondence: Girish Thunga,

Department of Pharmacy Practice, Manipal College of Pharmaceutical Sciences, Manipal Academy of Higher Education, Manipal, Karnataka, INDIA.

Phone: 9880151127

E-mail id: girishthunga77@ gmail.com

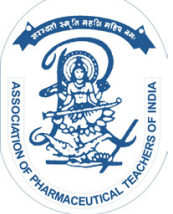

www.ijper.org 
riculum followed by almost all universities in India has not met the international standards and it makes the graduates to be far behind in the global scenario. ${ }^{5}$ There is no standardised pharma curriculum for graduates and post graduates till 2017. Pharm D syllabus is more patient centred and uniform all over the India. Pharm D syllabus is not upgraded even after the 9 years of course introduction. ${ }^{6}$ Ample number of Pharm D students are recruited in Pharmaceutical industries as Indian government has not paved the way for their recruitment as clinical pharmacists. This difference between what is taught, and the actual requirement of the industry create a gap between industry and academia. It incumbent a lot of financial burden on industries as they have to invest money for training and development of newly recruited students. Shivaji P.Gawade and Nitin P.Sonaje conducted a survey in academicians and industrial professionals to evaluate present undergraduates curriculum and reported that there is a need for revamping the curriculum and teacher's training to bridge the gap between college laboratory and industrial practice. ${ }^{7}$ Gouri Palsokar and Madhukar Tajne reported that a significant gap exists between skillsets required by industry and what students acquired during their postgraduation. ${ }^{8}$

Now the Pharmacy Council of India (PCI) has notified all the pharmacy colleges to implement the newly introduced syllabus for B. Pharm and M. Pharm courses. PCI has come forth such new regulation with an intention to make the syllabus more of industry-oriented to address the employment problem phased by the students by introducing uniform syllabus for the courses across the country. M.Pharm syllabus has been divided into credit based semester system and B.Pharm is semester system by 2017. ' Clinical research, pharmacovigilance and medical writing are the inevitable part of healthcare industry and most of the students are recruited in these sectors irrespective of their post-graduation disciplines. But practical aspects of clinical research, Pharmacovigilance and medical writing are excluded from the curriculum for both graduation and postgraduation. There is no practical session for clinical research in pharm D curriculum. ${ }^{10}$

Clinical research is relatively new field in our country. India is growing as the preferred landing place for clinical research for multinational companies because of its multitudes of benefits it offers. ${ }^{11}$ Each and every person from producers to consumers, trust the credibility of trials done and safety data provided by the clinical research personnel behind each new drug. The demand of science professional is $40 \%$ higher than that of other professionals. It is expected to grow by $13 \%$ over the next decade. ${ }^{12}$ The number of new drugs released per year is increasing and the chance of career opportunity in this field is also mounting. ${ }^{13}$ Drug development process is time consuming and it requires strict vigilance to ensure the safety and efficacy of drug. Safety of pharmaceutical product is not distinct, post effect of drugs which are using in combination with other drugs are unknown. Safety concerns in different groups are also different as children, pregnant women and geriatric people. ${ }^{14}$ Although demand of skilled qualified personnel are increased in these areas, academia is not able to produce graduates with adequate professional skills as regulatory reforms and technology upgradations are happening at a faster pace in industry. So periodic education and training are the much needed weapon to bridge the gap between academia and industry.

\section{Major flaws in Pharmacy Education}

Pharmacy courses (B.Pharm and M.Pharm) are mainly oriented towards the conventional needs of industry, and the contents are not updated as regulatory reforms and instrument upgradation are happening at a faster pace. Students are still getting unskilled way of practicals and practical equipments during their graduation span. Moreover practical aspects of the curriculum are not matching with the streamlined workflow. No one knows how much theory is connected to industrial practice or pharmacy practice or in what way they are connected with practical work. ${ }^{15}$ As per the new syllabus for M.Pharm by PCI, Clinical research is a course of study for Pharmacy practice and regulatory affairs. Basic concepts have been imparted or strengthened by theory wise. But there is a disconnect between theory and actual practice in areas like clinical research. For e.g obtaining informed consent is an imperative step in clinical trials as it is an ethical and legal requirement and procedure varies for literate, illiterates, paediatrics and special populations. Recently audiovisual recording also has been made mandatory in clinical trials. But in practical session they have only included preparation of informant consent form. There are no practical classes for interactive voice response system/ interactive web response system handling (IVRS/IWRS), screening, randomisation, coding, and decoding etc. Pharmcovigilance is another area of concern which is well imparted in theory wise. But practical aspects are not included in the curriculum such as safety reporting during the trial and postmarketing surveillance. Medical writing is not at all included anywhere. Curriculum is fully mugged up of theories in these areas rather than focusing actual practice-based aspects. So, students may not be able to connect theory with actual practice. Non-focused and unspecialized way of learning, outdated laboratory 
equipment's and infrastructure, lack of industrial exposure, teaching takes total priority over research and teachers' training are the other major areas of concerns impacting on pharmacy education in India.

\section{Strategies to improve the situation}

The ultimate solution to unravel this problem is either curriculum should be more focused or training programs on relevant areas to be conducted. Curriculum can be fostered, but it may not have focused on industrial relevant topic beyond a certain limit as it is a heterogeneous blend of industrial and clinical subjects. It should be flexible in terms of industrial needs. In the current scenario, it seems to be not practical. So proper designing of training module or industry oriented courses keeping all needs and requirements of industry made compulsory for every student based on their area of interest during their graduation span. These courses can be either developed by respective universities in collaboration with industries or industries can come forward and conduct training programs as per needs. We recommend the revision of curriculum based on following points

- Revise curriculum by focusing more actual practice oriented concepts rather than mugged up of theories, emphasizing latest technologies and techniques used in industries, and encouraging students and teachers for industrial training

- Develop industry oriented online or offline courses or training programs and make it compulsory

- Include case studies and simulation lab to get realistic experience in training programs and promote focused and specialised way of learning.

Why training programs are needed?

As per WHO, training is required if there is a gap between current status and desired status, to maintain the level of competence and to respond the new technologies and methods. ${ }^{16}$ A good training program is always targeted to address performance problem. Principle objectives of training are to enhance the knowledge, improve the attitudes and work behaviour and build and

strengthen the skills. Here the gap is little or no interaction between academia and industry and out dated course contents. So, training programs should be more focused on current industrial needs. An emphasis on the concept of case studies and simulation lab in training programs will strengthen the basic knowledge of graduates. Here it demands proper designing of training programs incorporating both basic knowledge and practical aspects which in turn will pave the way for the up gradation of pharmacy education.

Importance of Case studies and simulation lab in

\section{education}

By incorporating the case studies, students get deeper insights of a complex issue in its real life context. Case studies not only provide deeper understandings of the theory portion but also make the more complicated topic into simpler one. It helps the students to create the practical solution to the real dilemma. ${ }^{17}$ For e.g., case studies of adverse drug reaction, unanticipated problems involving risks to subjects, and informed consent procedure. The role of technology in pharmacy education is cardinal as the rate of growth and development of educational technology keeps increasing. Simulation lab in pharmacy education holds great potential in its ability to expose students to a variety of experiences. It provides realistic training and skills to students. ${ }^{18}$ This has already been implemented in medical education in foreign countries addressing the current gaps in education. ${ }^{19}$ For eg, a pharmacy student planning to go into Pharmaceutical industry as a clinical research associate may graduate without ever knowing the practical aspects of informed consent process or current PV practices. By participating in a full-environment simulation, a student can learn and practice the skills involved in such a situation.

\section{CONCLUSION}

Training programs can be introduced into the curriculum as skill development program and made compulsory for every student to attend the training program based on their area of interest during their graduation span. Initial basic knowledge regarding the work skills will help the fresher to accomplish their goals. Such training program should be more focused on industrial relevant area and can be conducted as joint venture of industry and institution. Industries should come forward and align the course content with industrial needs as part of industry academic collaborations for developing the training modules. Academia industry interaction should be encouraged and considered as part of education. In IT sector many companies have started collaboration with engineering colleges and universities. For example, Infosys has launched a program called Campus connect to align the education with the industrial need. ${ }^{20}$ Wipro also initiated one programme Wipro academy of software excellence in association with BITS (Pilani) to prepare the fresh graduates for careers. ${ }^{21}$ Curriculum should be finalised in consultation with industrial expert and review frequently. Revival of pharmacy education including the incorporation of training programs is the need of the hour, which in turn will pave the way to make our graduates more confident and competent. 


\section{CONFLICT OF INTEREST}

The authors declare no conflict of interest.

\section{REFERENCES}

1. Pharma Industry in India: Pharma Sector Overview, Market Size, Analysis IBEF [Internet]. Ibef org. 2017. [cited 17 April 2017]. Available from: https:// www.ibef.org/industry/pharmaceutical-india.aspx

2. Khosla V, Dasgupta B. Job market forecast: Take a look at how these 8 sectors will react to note ban in 2017 - The Economic Times [Internet]. The Economic Times. 2017. [cited 117 April]. Available from: http:// economictimes.indiatimes.com/jobs/take-a-look-at-how-these-8-sectors-willreact-to-note-ban-in-2017/articleshow/55948863.cms

3. Pharmaceutical Job Market Still Growing and Glowing [Internet]. Pubs acs org. 2017. [cited 17 April 2017].Available from: https://pubs.acs.org/ subscribe/journals/mdd/v03/i08/html/felton.html

4. Sahu H, Sultan A. Pharmaceutical education in India-Current scenario. International journal of development research. 2016;6(3):7049-52.

5. Jishnu V, Gilhotra RM, Mishra DN. Pharmacy education in India: Strategies for a better future. Journal of Young Pharmacists. 2011;3(4):334-42.

6. Pharm D. Course in India is struggling hard to reach the level of intl standard due to lack of updated syllabus [Internet]. Pharmabiz.com. 2018. [cited 10 May 2018]. Available from: http://www.pharmabiz.com/NewsDetails. aspx?aid $=100739 \&$ sid $=1$

7. Gawade S, Sonaje N. Designing of Curriculum Aspects of Pharmacy Undergraduate Course in Respect of Graduate Employability. Indian Journal of Pharmaceutical Education and Research. 2017;51(4):502-9.

8. Palsokar G, Tajne M. A Study on the Perceived Gap in Between Industry and Academia with Reference to the Curriculum of Post-Graduate Courses In Pharmaceutical Sciences in india. Indian Journal of Pharmaceutical Education and Research. 2018;52(1):10-20

9. $\mathrm{PCl}$ instructs colleges to implement new rules and syllabus for $\mathrm{B}$. Pharm $\mathrm{M}$. Pharm [Internet]. Pharmabiz.com. 2018. [cited 10 May 2018]. Available from: http://www.pharmabiz.com/NewsDetails.aspx?aid=99504\&sid=1
10. The Master of pharmacy course regulation, Scheme and syllabus. Pharmacy Council of india. 2016.

11. Booming Clinical Trial Market in India. RNCOS online business research. 2007.

12. Promising Futures for Scientific and Clinical Research Professional. Kelly Services India (internet). Kellyservices. Co.In. 2016. [cited 10 May 2018]. Available from: file:///E:/Documents/references/clinical\%20research/Sci_ PromisingFutures.pdf

13. WHO. The safety of Medicine in Public health programmes: Pharmacovigilance an essential tool. WHO Libr Cat Data (Internet). 2006;61. Available from:http://www.who.int/medicines/areas/quality_safety/safety_ efficacy/Pharmacovigilance_B.pdf

14. Kotturi N, Kotturi PK. Role of Pharmacovigilance in Health care Industry. Research and Reviews: Journal of Pharmacology and Toxicological studies. 2015;3(1):7-9.

15. Pharmacy education in India Is it future ready? [Internet]. BPD. 2018. [cited 10 May 2018]. Available from: http://www.expressbpd.com/pharma/ipc/ pharmacy-education-in-india-is-it-future-ready/395307/

16. World Health Organization. Designing and implementing training programs Human Resources Management. 2012;52.0-52

17. Crowe S, Robertson A, Huby G, Avery A, et al. Case study approach. BMC medical research methodology. 2011;11(1):100. Available from: http://www. biomedcentral.com/1471-2288/11/100

18. Lin K, Travlos DV, Wadelin JW, Vlasses PH, et al. Simulation and Introductory Pharmacy Practice Experiences. Am J Pharm Educ. 2011;75(10):209. Available from: https://www.ncbi.nlm.nih.gov/pmc/journals/383

19. Role of Simulation in Pharmacy Education - Learning Technologies Lab [Internet]. Learningtechlab. Pitt Edu. 2017. [cited 17 April 2017].Available from: http://learningtechlab.pitt.edu/index.php/2016/10/08/role-of-simulationin-pharmacy-education

20. Campusconnect. Infosys.Com. 2017. [cited 26 April 2017].Available from http://campusconnect.infosys.com/WhoWeAre.aspx

21. Wipro [Internet]. 2017. [cited 26 April 2017].Available from: http://careers wipro.com/campus-science-wase-2016.aspx

\section{SUMMARY}

- Contributer 1 is pursuing $\mathrm{PhD}$ in the same area. So, she has been done adequate literature search. Contributer 2, 3, 4 and 5 helped in the design of the paper, data acquisition, editing and review. Contributer 3 and 4 already published one article on "bridging the pharmaceutical education" in currents in pharmacy teaching and learning. Formerly said article focuses on the clinical pharmacy settings. They have developed and implemented some modules in postgraduate students in some selected area. They adopted problem based teaching and learning method. This elicited a positive response from students and good results were reflected in the students' assessment performance. Contributer2 has guided one thesis related to pharmacists' training programme. All above cited works are related to the area of hospital pharmacy and clinical pharmacy. Though pharmaceutical industries are the ultimate employer, curriculum is not much focused on the industrial relevant topics. We have already done one pilot study regarding "need assessment of professional training programme" in students by using questionnaire.

Cite this article: Balakrishnan A, Thunga G, Sreedharan, Vijayanarayana K, Khera K. Bridging the Gap Between Industry and Academia in Pharmaceutical Education. Indian $\mathrm{J}$ of Pharmaceutical Education and Research. 2018;52(4S):S7-S10. 